\title{
Chemical Identification and Cultural Implications of a Mixed Fermented Beverage from Late Prehistoric China
}

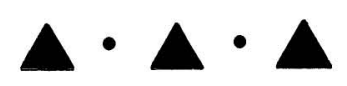

\author{
PATRICK E. McGOVERN, ANNE P. UNDERHILL, HUI FANG, \\ FENGSHI LUAN, GRETCHEN R. HALL, HAIGUANG YU, \\ CHEN-SHAN WANG, FENGSHU CAI, ZHIJUN ZHAO, \\ AND GARY M. FEINMAN
}

THE DISCOVERY AND REDISCOVERY of how to make a fermented beverage from a natural or derived source of simple sugars has occurred in many places and at many times. Before the modern period, only the Eskimos, the peoples of Tierra del Fuego at the southern tip of South America, and the Australian aborigines apparently lived out their lives without the medical benefits and mind-altering effects of alcohol, the principal drug in any fermented beverage. While polar regions lacked good resources for monosaccharides, honey and sugar-rich fruits and other plants are plentiful in temperate parts of the globe and the tropics. In the New World, maize (Zea mays) and the juice of the century plant (Agave americana) and the saguaro cactus (Carnegiea gigantea) were sweet enough to ferment directly into chicha, pulque, and cactus wine, respectively.

Increasingly, archaeological, ethnographic, and textual evidence from around the world points to fermented beverages, especially in the context of feasting activities, as integral to cultures at many different levels: social, religious, economic, and political. Although the goals and behaviors of participants and the scale of feasting and drinking varied (Bray 2003; Dietler and Hayden 2001; Hayden 1995; Potter 2000), feasts everywhere involved favorite foods and, almost invariably, fermented beverages. Feasts marked critical events in the lives of communities and individuals, and often entailed public rituals (Pauketat et al. 2002). Late pre-Hispanic Peru (Hastorf and Johannessen 1993; Moore 1989) exemplifies

Patrick E. McGovern is senior research scientist and adjunct associate professor at the University of Pennsylvania, Philadelphia. Gretchen R. Hall is a research assistant and Chen-shan Wang is a graduate student at the University of Pennsylvania Museum's Applied Science Center for Archaeology, Philadelphia. Anne P. Underhill is associate curator and Gary M. Feinman is curator and chair in the Anthropology Department at the Field Museum, Chicago. Hui Fang, Fengshi Luan, Haiguang $\mathrm{Yu}$, and Fengshu Cai are professors in the Department of Archaeology, Shandong University, China. Zhijun Zhao is a researcher at the Institute of Archaeology, Beijing, China. 
how great the demand for fermented beverages has been in the Americas, comparable to what is attested in the Old World (e.g., Iron Age Europe [Dietler 1990] and from the Neolithic period through historical times in the Near East and the Mediterranean region [Joffee 1998; McGovern et al. 1997; McGovern 2000, 2003]).

The demand for fermented beverages often led to social change. In Peru, this perceived need probably contributed to an intensification of maize production (Hastorf and Johannassen 1993). In Iron Age Europe, exchange systems were hard pressed to satisfy the craving of political elites for Italian wine (Dietler 1990). In the Middle East, the prestige exchange of wine and special winedrinking ceremonies have been proposed as the motive in the spread of a Neolithic wine culture, which came to encompass the region as a whole in the millennia that followed (McGovern et al. 1997).

How does ancient China fit into this picture of feasting and fermented beverage production and consumption that is so well documented elsewhere? Theoretical and methodological discussions have largely ignored this primal area of human civilization. Yet, abundant archaeological and textual evidence exists to demonstrate that fermented beverages, whether made from grains, fruit, or honey, were important in social, political, and ritual activities during the early Bronze Age of northern China.

Based on the readings of oracle bone and turtle shell inscriptions from the late Shang period (ca. 1200-1046 B.C.; Qiu and Cai 2001), the earliest writing in China, at least three beverages were distinguished: chang (an herbal wine), li (probably a sweet, low-alcohol rice or millet beverage), and jiu (a fully fermented and filtered rice or millet beverage or "wine," with an alcoholic content of probably 10-15 percent by weight) (see Childs-Johnson 1988; X. Fang 1989; H. T. Huang 2000:155-157, 259, passim; Underhill n.d.; Yang 1992; D. S. Zhang 1994). According to inscriptions, the Shang palace administration included officials who made the beverages, which were sometimes inspected by the king (Wen and Yuan 1983). Fermented beverages and other foods were offered as sacrifices to royal ancestors in various forms of bronze vessels (Guo 1986), likely accompanied by elite feasting (Keightley 1999; Underhill 2002). Later documents, incorporating traditions from the Zhou period (ca. 1046-221 в.c.), describe another two beverages: Iuo (likely made from a fruit) and lao (an unfiltered, fermented rice or millet beverage or the unfermented wort).

Numerous, magnificent bronze vessels have been recovered from sites of the Erlitou (ca. 1900-1500 в.C.), Shang (ca. 1600-1046 в.c.), and Western Zhou periods (ca. 1046-771 B.C.) (for detailed arguments about dating, see Lee 2002; Qiu and Cai 2001). Textual inferences and the forms of the vessels imply that they were used to prepare, store, serve, drink, and libate fermented beverages (Chang 1983; Childs-Johnson 1988; Rawson 1993; Thorp 1985; see also L. Liu 2003). At major centers such as Erlitou, Zhengzhou (earlier Shang period), and Anyang (late Shang period) (Figure 1), high-ranking individuals were buried with numerous ornate tripod vessels (jue and jia), stemmed goblets ( $g u$ ), vats $(z u n)$, and jars $(h u, l e i$, and you). Besides providing the dead with valued offerings for the afterlife, mourners likely drank fermented beverages during funerals. Ancestors and gods might have been consulted in the consequent altered state of consciousness (Paper 1995:32). 


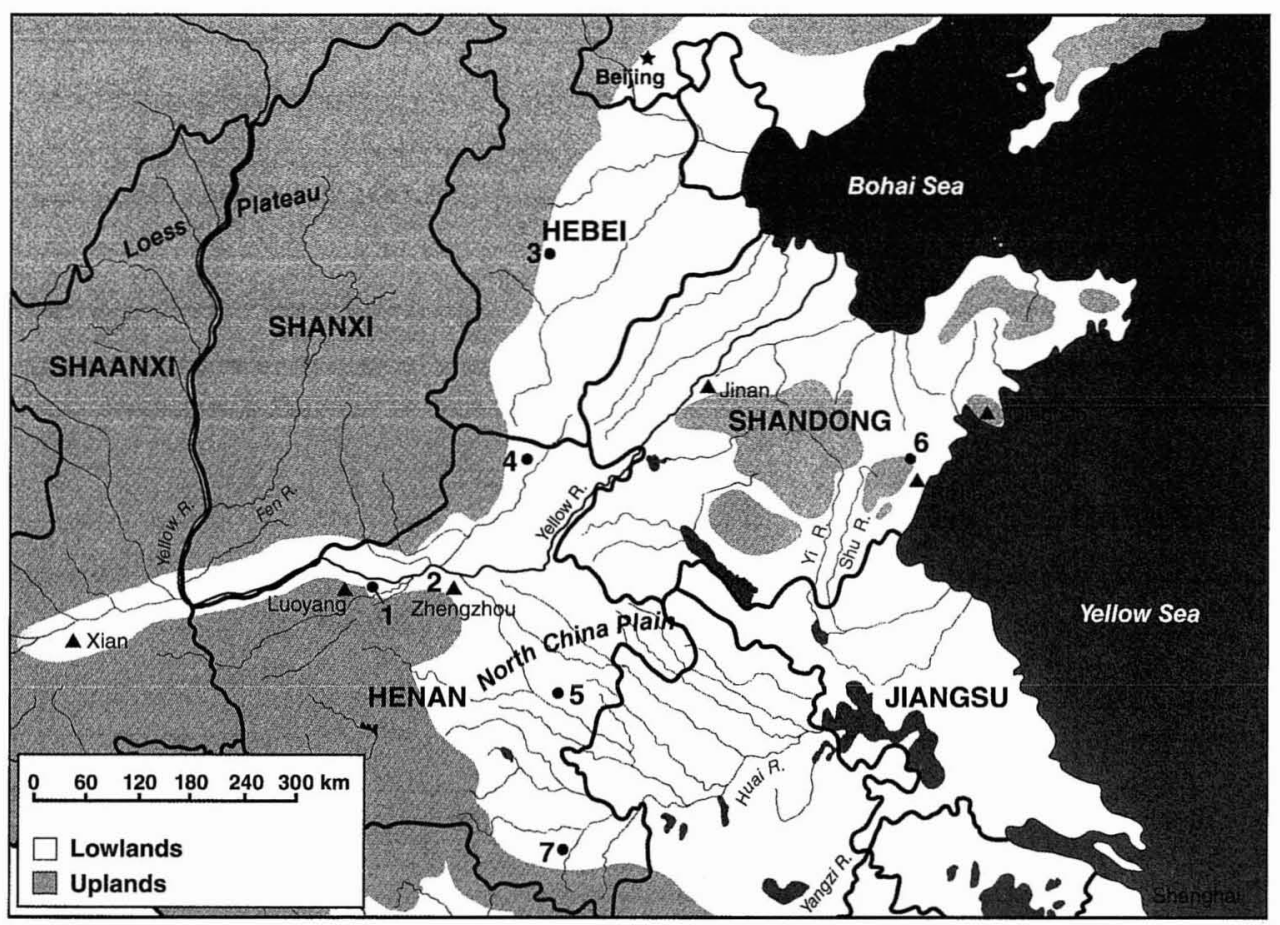

Fig. 1. Archaeological sites discussed in the text. $1=$ Erlitou, $2=$ Zhengzhou, $3=$ Taixi, $4=$ Anyang, 5 = Jiahu, $6=$ Liangchengzhen, $7=$ Tianhu.

Some jars in the tombs at Tianhu (CPAM 1986) and elsewhere were tightly stoppered, minimizing evaporation, and amazingly contained a liquid preserved for more than three millennia. Analyses of these liquids, which often have a fragrant aroma when the vessels are first opened, have been largely inconclusive and are unpublished. Positive evidence for yeast cells was obtained from an $8.5-\mathrm{kg}$ solid white residue inside a weng jar at Taixi (Hebei Province Institute of Cultural Relics and Archaeology 1985; Xing and Tang 1984; D. S. Zhang 1994), probably the lees of a fermented beverage. Habitation contexts at Taixi also yielded specific pottery forms that were likely used in beverage making, including a funnel and deep vat ("general's helmet") with a pointed, recessed bottom (H. T. Huang 2000:151-153; Underhill n.d.). Several jars at this site contained peach, plum, and Chinese date (jujube) pits, as well as seeds of sweet clover, jasmine, and hemp, suggesting that an herbal fruit drink was prepared.

A key question may be posed: Were fermented beverages important in social and ritual life during even earlier periods in northern China? Scholars (Y. Fang 1964; Fung 2000; J. M. Li 1984; Y. S. Li 1993; Yuan 1989) have long proposed that several Neolithic pottery forms, especially from the Dawenkou (ca. 41002600 B.c.) and Longshan (ca. 2600-1900 B.c.) periods in Shandong province, are so close in shape and style to the later bronze vessels that they were used to store, serve, and drink fermented beverages. Shandong province is especially well known for its numerous and elaborate drinking cups, found predominantly in burials. These become markedly more abundant during the late Dawenkou pe- 
riod (ca. 3000-2600 B.c.). Topics of research have included the spatial arrangement of vessels in tombs as a key feature of mortuary ritual (Fung 2000) as well as change in the nature of social ranking (Luan 1996; Underhill 2000, 2002).

The most elaborate form of ceramic drinking cup, the eggshell thin vessel, is found in a minority of burials from the Longshan period (L. Liu 1996a; Underhill 1996, 2002). There is agreement that multicommunity, regional polities existed at this time (L. Liu and Chen 2001). Whether these were chiefdoms (L. Liu 1996b; Underhill 1994) or states (Dematte 1999), however, is under debate. Underhill (2002) proposes that increased feasting activities in residential areas and for mortuary ritual created greater demand for prestigious foods, beverages, and vessels during the late Dawenkou and early-middle Longshan periods. This process played a role in the development of social stratification and caused diversification in ceramic production.

What has been lacking has been direct evidence from late prehistoric sites for the production of fermented beverages, from both residential and mortuary contexts. Based on the chemical analysis of extracted residues from ancient vessels found in Longshan period deposits at the site of Liangchengzhen, this paper provides the first evidence that fermented beverages were indeed produced and consumed during the late Neolithic period (for the early Neolithic period, see McGovern et al. 2004), preceding historical textual accounts.

\section{POTTERY SAMPLES TESTED FROM LIANGCHENGZHEN}

Systematic, regional survey has established that Liangchengzhen was a large regional center in southeastern Shandong province during the early, middle, and late phases of the Longshan period (Cai et al. 1997; H. Fang et al. 2002; Underhill et al. 1998, 2002). From 1999 to 2001, a Sino-American collaborative excavation, under the auspices of Shandong University, Yale University (1999), and the Field Museum (2000-2001), focused on the middle phase of the Longshan period, dated to ca. 2400-2200 B.C. in Shandong province. The pottery samples in this study (Table 1) represent three subphases (II, III, and IV; II being the earliest), and were recovered from undisturbed contexts in the main excavation area (Figure 2). We anticipated that any fermented beverage at the site would be made from rice (Oryza sativa) and/or millet (especially Setaria italica, the foxtail variety), since grains of these domesticated plants are well represented in flotation samples (Crawford et al. 2004, 2005).

For this study (also see McGovern et al. 2005), we deliberately selected a variety of Longshan pottery forms from Liangchengzhen. Two of these forms-the narrow-mouthed lei and $h u$ jars (Figure $3 e-f, h$ ) - were clear prototypes of Shangperiod bronze vessels that were associated with fermented beverages, according to scholarly consensus.

Cups and guan jars were the most prevalent and diverse groups of vessels from the Liangchengzhen excavations. We chose more than one cup variety (Figures $3 a-d$ and $4 a-e$ ) so that different forms, sizes, features, and wares were represented in the sample. We specifically targeted the form most commonly assumed to have been used to drink and libate fermented beverages during the Longshan period: the elegant, eggshell-thin, tall-stemmed gaobing bei cup (Figures $3 d$ and $4 d$ ). While it was not duplicated in bronze, scholars have proposed that it was used 
Table i. Analyzed Pottery Corpus

\begin{tabular}{|c|c|c|c|c|c|c|}
\hline SAMPLE NO. & $\begin{array}{l}\text { TYPE/PASTE AND } \\
\text { OTHER ATTRIBUTES }\end{array}$ & PHASE & CONTEXT & $\begin{array}{l}\text { COMMONLY INFERRED } \\
\text { FUNCTION }\end{array}$ & $\begin{array}{l}\text { CHEMICAL METHODS } \\
\text { EMPLOYED }\end{array}$ & INTERPRETATION \\
\hline 1 (Fig. $4 b$ ) & $\begin{array}{l}\text { Tongxing bei tubular } \\
\text { cup; moderate; } \\
\text { black; nearly whole }\end{array}$ & IV & $\begin{array}{l}\text { Pit H31:54, \#3207; } \\
\text { (upper pit); T2350 }\end{array}$ & Drink/libate beverages & $\begin{array}{l}\text { DRIFTS, HPLC, } \\
\text { GC-MS, + spot } \\
\text { test for tartrate }\end{array}$ & Mixed beverage \\
\hline 2 (Fig. 4d) & $\begin{array}{l}\text { Gaobing bei tall- } \\
\text { stemmed cup; fine; } \\
\text { black; upper piece } \\
\text { with cup rim only; } \\
\text { thin-walled }\end{array}$ & IV & $\begin{array}{l}\text { Pit H31:139, \#3223; } \\
\text { (lower part of large } \\
\text { pit); T2350 }\end{array}$ & Drink/libate beverages & $\begin{array}{l}\text { DRIFTS, HPLC, } \\
\text { GC-MS, - spot } \\
\text { test for tartrate, } \\
\text { + spot test for } \\
\text { oxalate }\end{array}$ & $\begin{array}{l}\text { Mixed beverage (possibly } \\
\text { with added barley) }\end{array}$ \\
\hline 3 (Fig. 4a) & $\begin{array}{l}\text { Zhixing bei cup (wider } \\
\text { base); moderate; } \\
\text { gray; whole cup }\end{array}$ & III & $\begin{array}{l}\text { Pit H60:1, \#4309; } \\
\quad \text { (one layer); T2302 }\end{array}$ & Drink/libate beverages & $\begin{array}{l}\text { DRIFTS, HPLC, } \\
\text { GC-MS, - spot } \\
\text { test for tartrate, } \\
\text { + spot test for } \\
\text { oxalate }\end{array}$ & $\begin{array}{l}\text { Mixed beverage (possibly } \\
\text { with added barley) }\end{array}$ \\
\hline 4 & $H u$ jar; coarse; black & IV & $\begin{array}{l}\text { Pit H31:37, \#3206; } \\
\text { (upper pit); T2350 }\end{array}$ & $\begin{array}{l}\text { Store and serve } \\
\text { beverages }\end{array}$ & $\begin{array}{l}\text { DRIFTS, HPLC, } \\
\text { + spot test for } \\
\text { tartrate }\end{array}$ & $\begin{array}{l}\text { Mixed beverage (possibly } \\
\text { with added barley) }\end{array}$ \\
\hline 5 & $\begin{array}{l}\text { Gui tripod; pale red } \\
\text { moderate; white } \\
\text { slip }\end{array}$ & IV & $\begin{array}{r}\text { Pit H71:1, \#4315; } \\
\text { (layer 2); T2302 }\end{array}$ & $\begin{array}{l}\text { Heat and store } \\
\text { beverages and } \\
\text { liquefied foods }\end{array}$ & $\begin{array}{l}\text { DRIFTS, HPLC, } \\
\text { GC-MS }\end{array}$ & Mixed beverage \\
\hline 6 (Fig. 4c) & $\begin{array}{l}\text { Zhixing bei cup (wider } \\
\text { base); moderate; } \\
\text { black; ring foot } \\
\text { whole base and } \\
\text { lower sidewalls }\end{array}$ & II & $\begin{array}{l}\text { Pit H116:1; \#4352 } \\
\quad \text { (one layer); T2303 }\end{array}$ & Drink/libate beverages & DRIFTS, HPLC & $\begin{array}{l}\text { Mixed beverage (possibly } \\
\text { with added barley) }\end{array}$ \\
\hline 7 & $\begin{array}{l}\text { Guan jar; coarse; black } \\
\text { and gray }\end{array}$ & III & $\begin{array}{l}\text { Pit H118:5, \#3851; } \\
\text { (layer 1); T2344 }\end{array}$ & $\begin{array}{l}\text { Store or cook solid } \\
\text { foods or liquids }\end{array}$ & $\begin{array}{l}\text { DRIFTS, HPLC, } \\
\text { GC-MS }\end{array}$ & $\begin{array}{l}\text { Mixed beverage (possibly } \\
\text { with added barley) }\end{array}$ \\
\hline 8 & $\begin{array}{l}\text { Tongxing bei tubular } \\
\text { cup; fine; black; } \\
\text { thin-walled }\end{array}$ & IV & $\begin{array}{l}\text { Pit H31:36, \#3206; } \\
\text { (upper pit); T2350 }\end{array}$ & Drink/libate beverages & $\begin{array}{l}\text { DRIFTS, HPLC, } \\
\text { + spot test for } \\
\text { tartrate }\end{array}$ & Mixed beverage \\
\hline
\end{tabular}


Table I (Continued)

\begin{tabular}{|c|c|c|c|c|c|c|}
\hline SAMPLE NO. & $\begin{array}{l}\text { TYPE/PASTE AND } \\
\text { OTHER ATTRIBUTES }\end{array}$ & PHASE & CONTEXT & $\begin{array}{l}\text { COMMONLY INFERRED } \\
\text { FUNCTION }\end{array}$ & $\begin{array}{l}\text { CHEMICAL METHODS } \\
\text { EMPLOYED }\end{array}$ & INTERPRETATION \\
\hline 9 & $\begin{array}{l}\text { Guan jar; coarse; dark } \\
\text { gray }\end{array}$ & III & $\begin{array}{l}\text { Pit } \mathrm{H} 115: 15, \# 1666 ; \\
\quad \text { (layer 1); T2049 }\end{array}$ & $\begin{array}{l}\text { Store or cook solid } \\
\text { foods or liquids }\end{array}$ & $\begin{array}{l}\text { DRIFTS, HPLC, } \\
\quad+\text { spot test for } \\
\quad \text { tartrate }\end{array}$ & Mixed beverage \\
\hline 10 (Fig. 4f) & $\begin{array}{l}\text { Gui tripod; moderate; } \\
\text { orange-red; nearly } \\
\text { whole }\end{array}$ & III & $\begin{array}{l}\text { Pit H48:10, \#4305; } \\
\text { (layer 1); T2302 }\end{array}$ & Drink/libate beverages & $\begin{array}{l}\text { DRIFTS, HPLC, } \\
\text { GC-MS, } \\
\text { borderline + spot } \\
\text { test for tartrate }\end{array}$ & Mixed beverage \\
\hline 11 (Fig. 4g) & $\begin{array}{l}\text { Ding sieve; coarse; } \\
\text { brown-gray; small } \\
\text { holes }\end{array}$ & $?$ & $\begin{array}{l}\text { Surface find, eastern } \\
\text { part of site }\end{array}$ & $\begin{array}{l}\text { Probable strainer for } \\
\text { beverages }\end{array}$ & $\begin{array}{l}\text { DRIFTS, HPLC, } \\
+ \text { spot test for } \\
\text { tartrate }\end{array}$ & uncertain \\
\hline 12 (Fig. $4 e$ ) & $\begin{array}{l}\text { Ding-shaped cup; } \\
\text { coarse; black }\end{array}$ & III & $\begin{array}{l}\text { Pit H115:1, \#1666; } \\
\text { (layer 1); T2049 }\end{array}$ & Drink/libate beverages & $\begin{array}{l}\text { DRIFTS, HPLC, } \\
\text { GC-MS, + spot } \\
\text { test for tartrate, } \\
\text { borderline + spot } \\
\text { test for oxalate }\end{array}$ & $\begin{array}{l}\text { Mixed beverage (possibly } \\
\text { with added barley) }\end{array}$ \\
\hline 13 & $\begin{array}{l}\text { Guan jar; moderate; } \\
\text { gray }\end{array}$ & III & $\begin{array}{l}\text { Pit H114:4; \#1665; } \\
\quad \text { (one layer); T2049 }\end{array}$ & $\begin{array}{l}\text { Store or cook solid } \\
\text { foods or liquids }\end{array}$ & $\begin{array}{l}\text { DRIFTS, HPLC, } \\
\text { GC-MS, + spot } \\
\text { test for tartrate }\end{array}$ & Mixed beverage \\
\hline 14 & $\begin{array}{l}\text { Large } h u \text { jar; coarse; } \\
\text { brown-black }\end{array}$ & III & $\begin{array}{l}\text { Pit H118:6, \#3851; } \\
\text { (layer 1); T2344 }\end{array}$ & $\begin{array}{l}\text { Store fermented } \\
\text { beverages }\end{array}$ & $\begin{array}{l}\text { DRIFTS, HPLC, } \\
\text { + spot test for } \\
\text { tartrate }\end{array}$ & Mixed beverage \\
\hline 15 & $\begin{array}{l}\text { Tongxing bei tubular } \\
\text { cup; fine; black }\end{array}$ & IV & $\begin{array}{l}\text { Pit H31:6, \#3206; } \\
\quad \text { (upper pit); T2350 }\end{array}$ & Drink/libate beverages & DRIFTS, HPLC & Mixed beverage \\
\hline 17 & $\begin{array}{l}\text { Small } h u \text { jar; fine; } \\
\text { black; polished; } \\
\text { thin-walled }\end{array}$ & IV & $\begin{array}{l}\text { Grave M22:1, \#3857; } \\
\text { T2344 }\end{array}$ & $\begin{array}{l}\text { Store and serve } \\
\text { beverages }\end{array}$ & DRIFTS, HPLC & Mixed beverage \\
\hline 18 & $\begin{array}{l}\text { Tongxing bei tubular } \\
\text { cup; fine; black }\end{array}$ & IV & $\begin{array}{l}\text { Grave M22:3, \#3857; } \\
\text { T2344 }\end{array}$ & Drink/libate beverages & DRIFTS, HPLC & Mixed beverage \\
\hline 19 (Fig. 4h) & $\begin{array}{l}\text { Bizi steamer rack; } \\
\text { coarse; dark gray; } \\
\text { large holes; } \\
\text { rectangular }\end{array}$ & III & $\begin{array}{l}\text { Pit H61:2, \#4107; } \\
\quad \text { (one layer); T2342 }\end{array}$ & $\begin{array}{l}\text { Steam cereals and } \\
\text { foods }\end{array}$ & $\begin{array}{l}\text { DRIFTS, HPLC, } \\
\quad+\text { spot test for } \\
\text { tartrate }\end{array}$ & Mixed beverage \\
\hline
\end{tabular}


Sanzu three-footed bei cup; coarse; black

Guan-shaped bei cup; moderate; black

thin-walled

Guan jar; coarse; gray

Ding tripod; coarse; orange-red

Guan jar; moderate; black; polished

Pen basin; moderate; black; polished; relatively thinwalled

Pen basin; coarse; dark gray

Lei jar; fine; black; polished; mid-body with handle

Gui leg with lower body; soapstone coarse; orange-red T2447 T2445

Pit H199:17, \#4416; (layer 2); T2397

\section{Pit H205:3, \#3322;} (layer 1); T2400

III

Pit H215:13, \#3327; (layer 1); T2400

III

Pit H199:3, \#4416; (layer 2); T2397

Pit H105, \#1654; (one layer); T2049

\section{Pit H31, \#3204;} (upper pit); T2350

\section{IV $\quad$ Pit H31, \#3204;} (upper pit); T2350
Drink/libate beverages

DRIFTS, HPLC

Drink/libate beverages

DRIFTS, HPLC

Store or cook solid foods or liquids

Cook food, especially meat dishes

Store or cook solid foods or liquids

Prepare foods and beverages

Prepare foods and beverages

Store and serve beverages

Heat and serve beverages and liquefied foods

DRIFTS, HPLC, GC-MS, test for tartrate

DRIFTS, HPLC, GC-MS

DRIFTS, HPLC

DRIFTS, HPLC, test for tartrate

DRIFTS, HPLC

+ spot test for tartrate

DRIFTS, HPLC,

+ spot test for tartrate
Mixed beverage (possibly with added barley)

Mixed beverage

+ spot test for tartrate uncertain

borderline + spot

Mixed beverage

Mixed beverage GC-MS, + spot

Note: Samples are base sherds or lower sidewalls, unless noted otherwise. Paste $=$ tempered with fine, moderately large or coarse inclusions. Middle Longshan Period Phase (ca. 2400-2300 B.C.E.) = II, III, or IV (from early to late). Numbers such as T2445 refer to excavation units; our individual vessel numbers appear after colons. Numbers such as \#1354 refer to distinct depositional contexts. For pits, layer 1 is top layer. Samples 16,21 , and 27 are omitted since these vessels were from poor archaeological contexts. An exception was made for sample 11, because it is a unique form. Chemical methods (DRIFTS, HPLC, and GC-MS) are defined in text. 


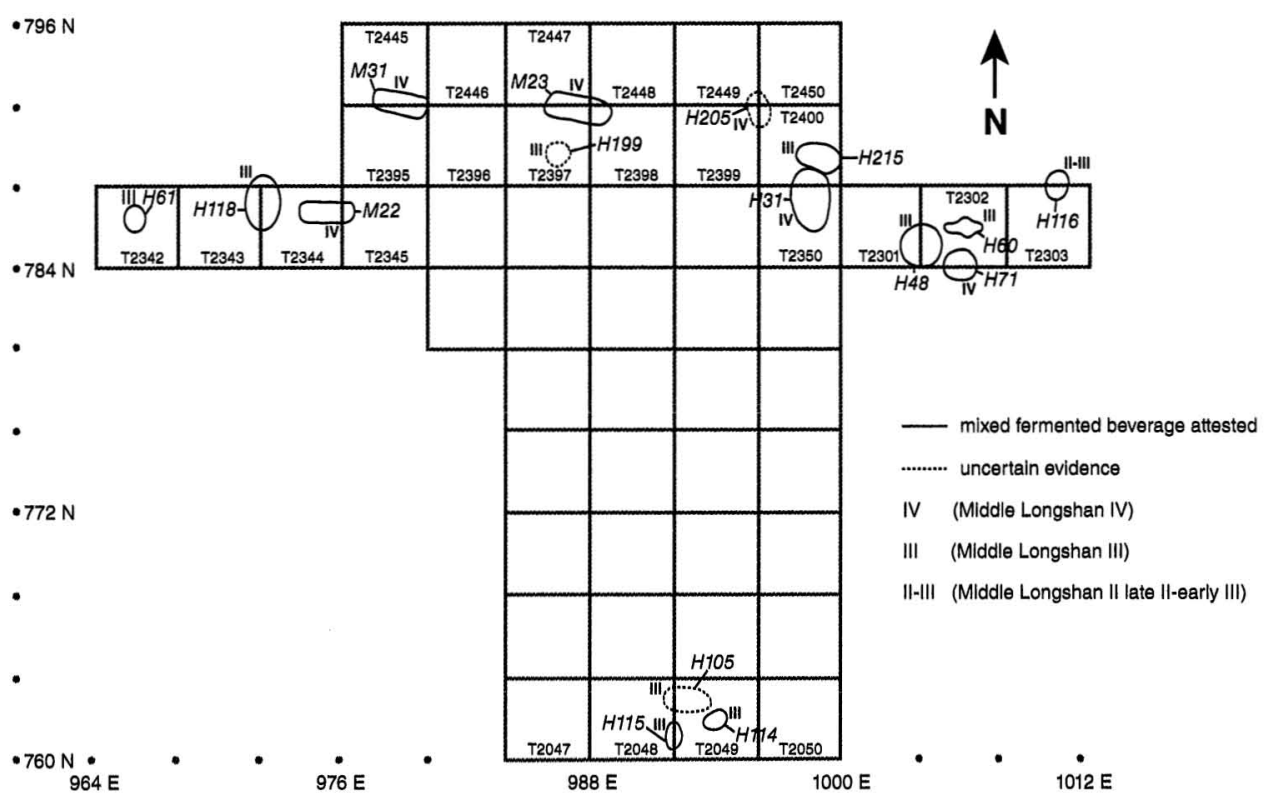

Fig. 2. Location of features with samples at Liangchengzhen.

for special drinks or liquefied foods, comparable to the employment of elegant bronze cups in historical times. The generic guan jar (Figure $3 g$ ), with a relatively wide mouth and body, probably had multiple functions. If carbon deposits are observed on its exterior, it likely was used for cooking (Y. H. Zhang and D. H. Zhang 1986:47, 49), whereas examples found near wells were likely for carrying water (Institute of Archaeology 1984:84).

Scholars also agree that the gui tripod (Figures $3 j$ and $4 f$ ), with its bulbous and hollow legs, could have been used to heat a fermented beverage or a liquified food (Luan 1992:250; R. Wang 1997:183). This elegant vessel form was recovered in unusually high numbers and varieties at Liangchengzhen. The ding tripod with solid legs (Figure 3k), a likely general forerunner of the Shang period bronze ding, is traditionally associated with cooking solid foods.

The analytical corpus also included a unique ding sieve (Figure $4 g$ ) and a bizi "steamer rack" (Figure 4h). The pen basin (Figure 3i) could have been used in a variety of activities for preparing and serving food or beverages.

Since residue analysis has sometimes been subsumed under use alteration studies in the anthropological literature (e.g., Skibo 1992), it needs to be stressed here that no visible residues were observed on the surfaces of any pottery chosen for analysis. None of the pieces showed signs of spalling or pitting on their interiors, which has sometimes been correlated with acidic fermented beverages (e.g., Arthur 2003). Degradation of pottery is highly dependent on the clays used, their salinity, and pottery-making techniques (levigation, tempering, and firing). The Liangchengzhen pottery was generally well made and high-fired (Luan et al. in press), so that it suffered minimally from groundwater and other geological factors. When such disintegration of pottery fabrics is observed in an archaeological 


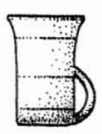

a

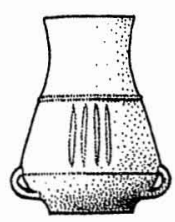

b

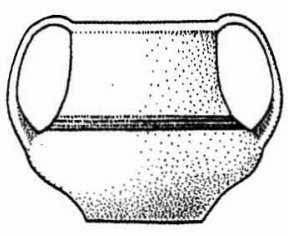

C

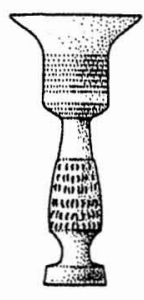

d

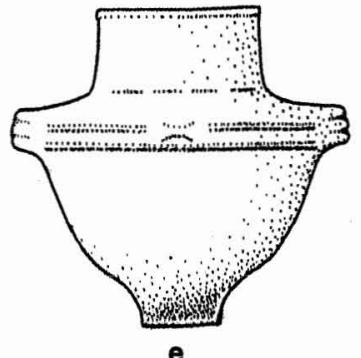

$\mathbf{e}$
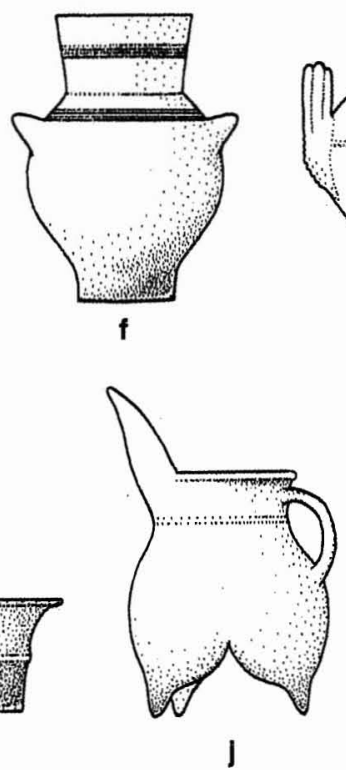

J
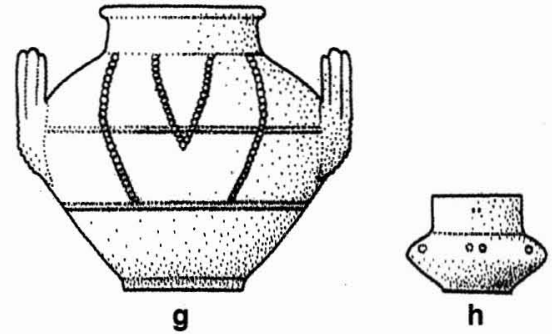

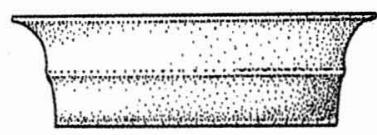

I

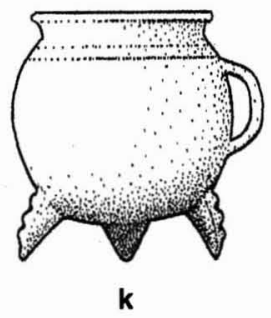

Fig. 3. Representative Liangchengzhen whole vessels illustrating pottery forms chosen for organic residue analysis (nos. a, i, j, k from Yin 1955: Fig. 2; others from Rizhao City Library and Linyi District Committee for Management of Cultural Relics 1986:686-687, 696, Figs. 8, 9, 18). $a=$ tongxing bei/tubular cup; $b=$ zhixing bei/cup, which is more bulbous near base; $c=$ globular guan jar-shaped cup with handles; $d=$ gaobing bei/tall-stemmed cup; $e=l e i$ carinated jar; $f=h u$ jar with round shoulders; $g=$ guan jar with handles; $h=$ small $h u$ jar; $i=$ pingdi ("flat") pen basin with flat base and outwardly splayed sidewalls; $j=$ gui tripod; $k=$ ding tripod.

site, possible alteration by natural causes and/or other highly acidic or alkaline foods and beverages must be excluded before concluding that the vessels contained a fermented beverage.

\section{CHEMICALLY IDENTIFYING THE ANCIENT BEVERAGE}

The Molecular Archaeology Laboratory of the University of Pennsylvania Museum's Applied Science Center for Archaeology (MASCA) carried out analyses on twenty-seven ancient organic samples from Liangchengzhen, all dating to various phases of the middle Longshan period. Four chemical techniques were 


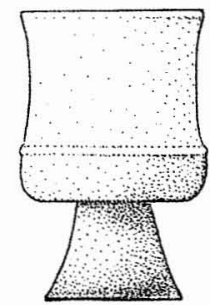

a



b

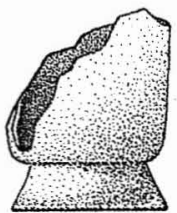

C

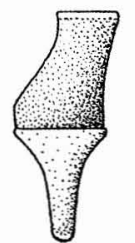

d

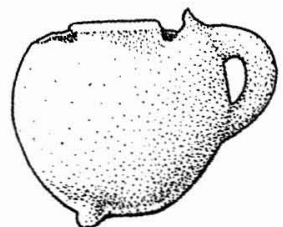

e
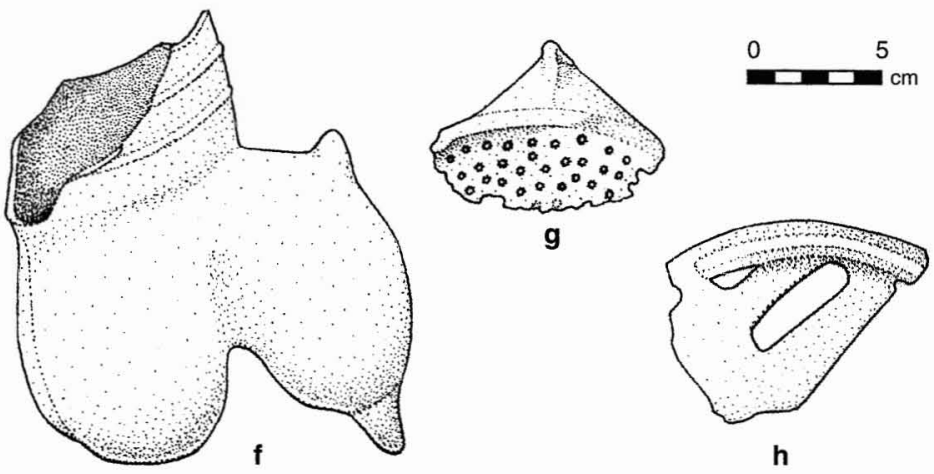

Fig. 4. Analyzed pottery from Liangchengzhen (1999-2000). $a=$ zhixing bei cup, H60:1, \#4309; $b=$ tongxing bei cup $\mathrm{H} 31: 54, \# 3207 ; c=$ zhixing bei cup, H116:1, \#4352; $d=$ gaobing bei tallstemmed cup, upper portion only, H31:139, \#3223; $e=$ ding-shaped cup, H115:1, \#1666; $f=$ gui tripod, H48:10, \#4305; $g$ ding sieve foot, surface find; $h=b i z i$ steamer rack piece, H61:2, \#4107.

used to identify the constituents of the ancient residues (for details, see the appendix). If results from the four independent chemical methods are in agreement, then a compound is said to be present. Detecting fingerprint or marker compounds of specific natural products is especially important, and our laboratory protocols are designed to target these compounds.

The samples tested were generally base sherds of the ancient pottery vessels, which absorb more liquid and thus are where precipitates accumulate. They were extracted by twice boiling in methanol or chloroform for 20 minutes. The two portions were combined, filtered to remove fine particles $>5-10 \mu \mathrm{m}$ diameter, and gently evaporated to dryness. The volume of solvent used depended on the size of the sherd, which was totally submerged in the solvent. Prior to extraction and following excavation, the sherds had been washed gently in water to remove adhering soil. The total amount of solid extract obtained from each sherd ranged from about 1 to $10 \mathrm{mg}$, depending upon the sherd's size and thickness and the amount of absorbed organic material.

It should be stressed that there are no "magic bullets" for detecting an ancient organic compound. The available microchemical techniques must be applied discriminately, often in combination, to specific problems. Given the limited preservation of the archaeological record, as well as chemical and microbial changes with time, determining the natural source of a given compound and its signifi- 
cance can be fraught with difficulties. Archaeology, as a historical science, also does not allow for repeating a past event by modern experimentation, the usual requirement for proving a hypothesis in the physical sciences. The coherence of the archaeological and chemical data must be assessed in each instance, and a judgment made as to which hypothesis best accounts for the available evidence.

Sometimes, unequivocal chemical confirmation-e.g., for royal purple dye (McGovern and Michel 1990) - is achievable. Recently, a more sensitive technique for tartaric acid detection (Guasch-Jané et al. 2004) was used to analyze ancient Egyptian vessels, and provided confirmation for our findings that this fingerprint compound for grape wine in the Middle East (below) is well preserved in pottery fabrics. More often, however, chemical identification and its significance is less certain because of environmental and microbial degradation, modern contamination, human processing in antiquity, the degree to which a region's natural resources have been adequately surveyed for biomarkers, and other factors. Illustrative of this problem, the reader will note the column in Table 1 that cites the commonly inferred functions of ancient vessel forms based on texts, ethnographic analogy, and modern usage. On occasion, the chemical results will diverge from these standard interpretations (e.g., for the bizi steamer rack no. 19 and the pen basin no. 26). In that case, other hypotheses need to be considered and tested, as proposed below.

Extracts of twenty-three ancient pottery samples from Liangchengzhen yielded very similar chemical results. A range of vessel forms (Figure 4) was represented in this large group, including ten bei cups of five different forms (sample nos. 1, 2, 3, $6,8,14,15,18,20$, and 22 in Table 1), three gui tripods (nos. 5, 10, and 30), three $h u$ jars (nos. 4, 14, and 17), four guan jars (nos. 7, 9, 13, and 25), one lei jar (no. 29), one bizi steamer rack (no. 19), and one pen basin (no. 26). Only four vessels in the corpus gave uncertain chemical results and were not members of the large group: nos. 11 and 24 (ding tripods), no. 23 (guan jar), and no. 28 (pen basin).

Figure $5 a$ highlights the principal infrared (IR) absorptions for the large chemically consistent group of twenty-three samples. At the left, the broad band centered around $3400 \mathrm{~cm}^{-1}$ is due to hydroxyl or water of hydration. The sharp, intense peaks at 2920 and $2850 \mathrm{~cm}^{-1}$, as well as the absorption at $730-720 \mathrm{~cm}^{-1}$, are the result of long straight-chain hydrocarbons (e.g., n-alkanes), which are accentuated in the chloroform extracts. Some hydrocarbon absorption, in conjunction with the small peak at $1790 \mathrm{~cm}^{-1}$ and a possible $\gamma$-lactone carbonyl absorption in the $1690-1670 \mathrm{~cm}^{-1}$ range, may also be due to an as yet unidentified plant resin or herb, as implied by previous research on ancient Near Eastern wine (McGovern et al. 1996, 1997).

According to gas chromatography-mass spectrometric (GCMS) analysis (Figure 5b), $\mathrm{C}_{23} \mathrm{H}_{48}, \mathrm{C}_{25} \mathrm{H}_{52}, \mathrm{C}_{27} \mathrm{H}_{56}$, and $\mathrm{C}_{29} \mathrm{H}_{60}$-characteristic n-alkanes in beeswax and thus marker compounds of honey (Evershed et al. 1997; Xu et al. 1989) possibly account for the straight-chain hydrocarbon IR absorptions. Alternatively, these n-alkanes, with the $\mathrm{C}_{29}$ compound usually most prominent (Kolattukudy 1976), might be explained by epicuticular waxes, which occur on the surfaces of leaves and fruits of many plants. Further complicating the picture, intervening even-numbered n-alkanes at lower levels have been observed in degraded plant material (Lockheart et al. 2000; Tu et al. 2001). Since such even-numbered com- 

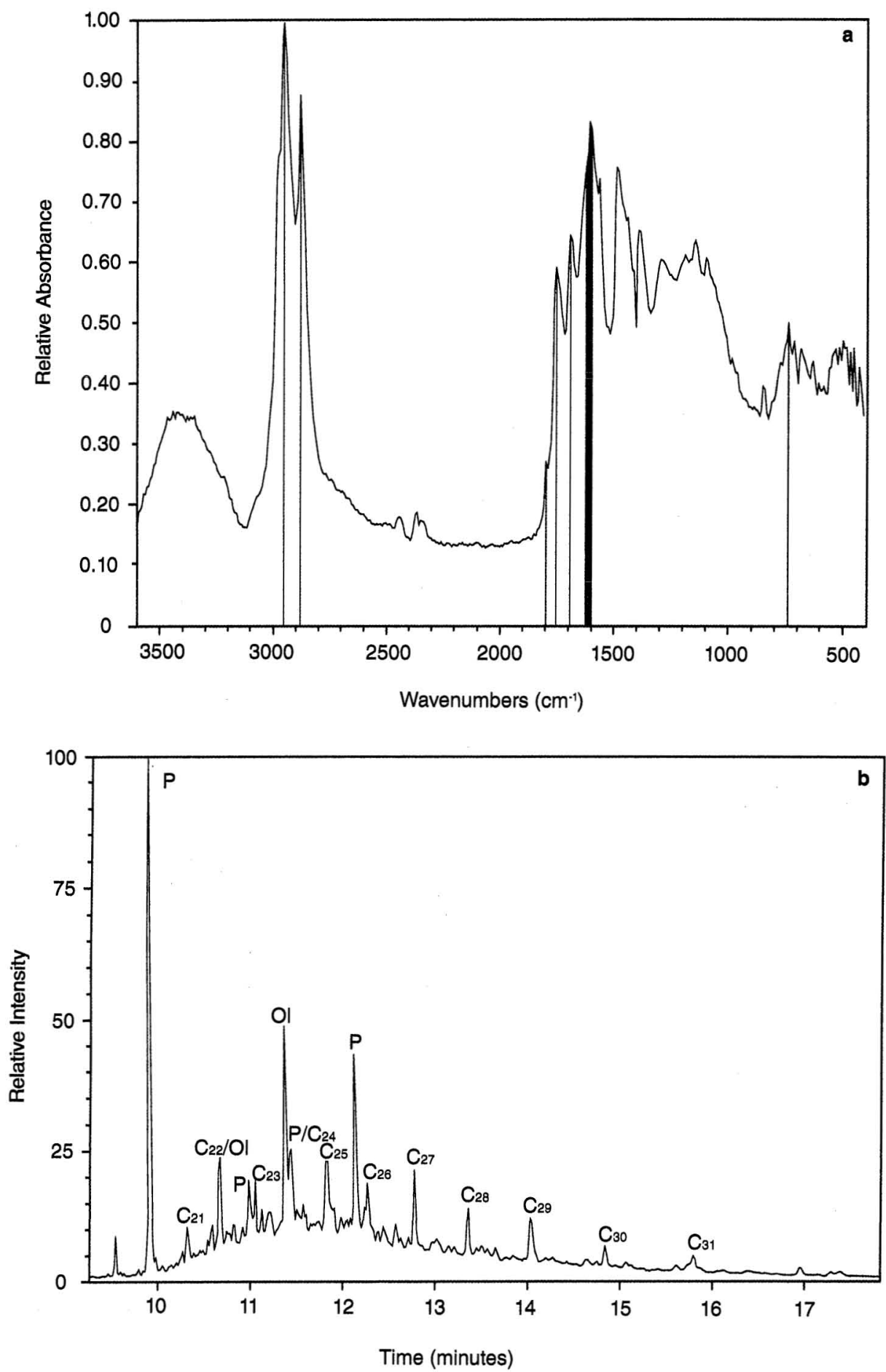

Fig. 5. Representative chemical results for Liangchengzhen mixed fermented beverage. $a=$ DRIFTS spectrum of sample no. 1 (methanol extract), a tongxing bei tubular cup, showing the principal absorptions of the mixed fermented beverage of rice, honey, and fruit. Spectra deresolved at $8 \mathrm{~cm}^{-1}$ wavenumber. See text for discussion. $b=$ GC/MS analysis of sample no. 2 (chloroform extract), total ion chromatogram, a gaobing bei tall-stemmed cup, showing the homologous paraffin series from $\mathrm{C}_{21}$ to $\mathrm{C}_{31}(\mathrm{P}=$ phthlate contaminant; $\mathrm{Ol}=$ oleamide contaminant). Chinese beeswax has elevated levels of the odd-numbered members of the series. 
pounds are also present in the Liangchengzhen extracts, they might be explained as degradation of the beeswax and/or epicuticular wax originally present in the archaeological samples. Deep-lying earth waxes (ozokerites), associated with coal or petroleum deposits, can also yield a similar range of n-alkanes (Mills and White 1994:53; White 1978:60), but such deposits are as yet unattested in the Liangchengzhen region.

Tartaric acid, the principal organic acid in grape wine and also occurring in other Chinese natural sources (see below), probably accounts largely for the intense absorption peaks in the $1720-1740 \mathrm{~cm}^{-1}$ region, occurring either as a doublet or as the $1740 \mathrm{~cm}^{-1}$ peak with a shoulder (compare Figure $5 \mathrm{a}$ ). Some contribution from tannins, resins, waxes, and other compounds with carbonyl acid groups, however, cannot be ruled out. These natural products and other compounds can be partly distinguished by examining their spectra for greater complexity in the carbonyl region above $1740 \mathrm{~cm}^{-1}$ (most indicative of a tree resin). The hydroxyl bending band at $1435-1445 \mathrm{~cm}^{-1}$ is decisive for tartaric acid, since other important hydroxyl compounds derived from natural sources and of archaeological interest (e.g., tree resins, beeswax, and plant waxes) absorb at a higher frequency, viz., $1460-1465 \mathrm{~cm}^{-1}$.

Similarly, a tartrate salt, which is more insoluble than the acid and would be expected to precipitate out of solution, is especially pronounced in the samples, correlating with carboxylate absorptions at maxima of 1610 and $1580 \mathrm{~cm}^{-1}$, with additional peaks at $1460,1420,1370$, and $1270 \mathrm{~cm}^{-1}$. The presence of tartaric acid/tartrate was further borne out by positive Feigl spot tests for ten samples in the large group (Table 1). The borderline or negative results for three samples (nos. 2, 3, and 10) is most likely explained by the small amounts available for analysis. Similarly, another ten samples could not be run because of their small sizes.

When searched for the closest matches in our IR databases, the large group of twenty-three samples were chemically most similar to one another, as might be expected if the vessels originally contained or were used to process a similar liquid. Modern rice and rice wine provided excellent IR matches. Most of the samples also had very close IR matches with extracts of pottery jars from Jiahu, an early Neolithic village in Henan province, radiocarbon dated to 7000-5500 B.C. for the pottery that was tested (Henan Provincial Institute of Cultural Relics and Archaeology 1999; McGovern et al. 2004). Additionally, most of the Liangchengzhen samples were chemically similar to ancient Near Eastern resinated wine and/or a mixed beverage of wine, barley beer, and honey mead from the ancient Mediterranean region (McGovern et al. 1999; McGovern 1999-2000). In several instances, grape and terebinth tree resin, often the additive of choice in ancient Near Eastern wines, provided matches.

The most informative peaks in the high-performance liquid chromatographic (HPLC) chromatograms came at retention times of about 1.55 and $1.65 \mathrm{~min}$. The UV spectra of the twenty-three samples in the large group matched one another most closely at these times, implying that they originally contained a similar natural product as also borne out by the IR evidence (above). Other wellattested, frequent matches included rice and rice wine, potassium gluconate (the salt of the principal acid in honey), beeswax, and terebinth tree resin. Additionally, modern barley and calcium oxalate or beerstone, a marker compound for barley beer fermentation (Michel, Lazar, and McGovern 1992; Michel, Mc- 
Govern, and Badler 1992), gave good HPLC matches for six samples: nos. 2, 3, 4, 6,7 , and 12, including two zhixing bei cups, a gaobing bei tall-stemmed cup, $h u$ and guan jars, and a ding-shaped cup. Although the statistical matches for barley and calcium oxalate do not provide absolute confirmation of the presence of this natural product or compound, they are consistent with other lines of evidence. For example, these samples showed organic acid absorption at the higher end of the salt bands, between 1670 and $1610 \mathrm{~cm}^{-1}$ and sometimes at 1505 and $1320 \mathrm{~cm}^{-1}$, as is characteristic of calcium oxalate. Nos. 2, 3, and 12, which were large enough to run spot tests, gave positive results for oxalate. Two Jiahu samples, ancient Near Eastern resinated wine, and the mixed Mediterranean beverage rounded out the HPLC evidence for ancient matches to the chemically homogeneous group of Liangchengzhen pottery.

\section{A MIXED FERMENTED BEVERAGE}

The combined chemical results for the large group of twenty-three Liangchengzhen samples are best explained as a mixed fermented beverage composed of rice, honey, and a fruit, possibly with barley and a plant resin (or herb) as additives (listed in the last column of Table 1). A beverage in which rice was a principal ingredient accords with archaeobotanical findings thus far. Millet, which is also well represented at Liangchengzhen, does not appear to have been used in making the beverage, although barley-yet to be identified archaeobotanically-is suggested by the chemical evidence. At present, although it is not clear when barley was introduced into China or domesticated there, an early date is implied by the finding of archaeobotanical samples as early as ca. 1000 B.C. in Japan and Korea, across the Yellow Sea from Shandong province (Crawford 1992:21-22).

The $\mathrm{C}_{21}-\mathrm{C}_{31} \mathrm{n}$-alkanes mark the presence of epicuticular wax and/or beeswax. If the latter, then these would be marker compounds of honey, because beeswax is virtually impossible to filter out completely when processing honey and its compounds can be very well preserved. By contrast, the sugars in honey-mainly fructose and glucose-rapidly degrade and are lost. Honey is a unique concentrated source of simple sugars (60-80 percent by weight) in temperate climates around the world, and humans discovered and exploited it as a sweetener at an early date. The earliest documentary mention of a honey beverage is from the Warring States period (ca. 480-221 B.C.-Morohashi 1987:10487-10489), and rice and honey were fermented together into a beverage in the Tang period (618-906 A.D.-H. T. Huang 2000:247-248). Today, China is the third largest producer of honey in the world, and produces a mead from a mountain honey in Shaanxi province (Shusen 2001).

Another possibility is that the n-alkane evidence signals the presence of a wax intentionally used to seal the porous pottery fabric. However, none of the pottery thus far recovered from Liangchengzhen shows any sign of a wax coating, and documentary evidence for the use of wax in sealing jar mouths and as an antifoaming agent occurs much later $(\mathrm{H}$. T. Huang 2000:183-188, citing the Bei Shan Jiu Jing [Wine Canon of North Hill] by Hong Zhu [1964:1243-1244]). A telling line in the Xin Xiu Ben Cao (Newly Improved Pharmacopoeia; 1985: ch. 19 [Mi Deng Bu], p. 287) of the seventh-century C.E. Tang Dynasty pharmacist Su Jing helps explain why honey was an ideal starting material: "grape wine and 
honey mead do not require a fermentation agent [qu-see below]." Long before Louis Pasteur identified yeast cells microscopically and described their metabolism, ancient Chinese beverage makers likely understood the practical importance of surface froth on mead and grape wine for initiating fermentation. Honey contains natural osmophilic yeasts, which can tolerate high sugar levels. When diluted with 70 percent water, these organisms become active and produce mead. Because the principal yeast species, Sacharomyces cerevisiae, is not airborne, the success of the fermentation was assured by using honey as an ingredient or additive.

The presence of tartaric acid/tartrate in the ancient Liangchengzhen beverage raises the prospect that the Neolithic beverage maker also used grape as a source of yeast and sugar. Fermentation begins as soon as the juice is exuded from the fruit. With more than fifty native wild grape species (F. Zhang et al. 1990), China accounts for more than half of the species in the world. The wild fruit is often sweet enough (up to 19 percent sugar by weight, which can be further concentrated by raisining) that wine is made from grapes today (e.g., Vitis amurensis, $V$. quinquangularis Rehd./ $V$. pentagona Diels and Gilg). As many as ten wild species grow in eastern Shandong province today, which is considered part of the region where Vitis originated in China. Yet, grape is poorly attested at prehistoric Chinese sites. To date, only three grape pips have been recovered from Longshan contexts at Liangchengzhen. Zhijun Zhao, a coauthor of this paper, has also identified similar grape pips from early Neolithic Jiahu, which morphologically appear to be of a wild species, and Kong et al. (1999) report comparable evidence from the Longshan period site of Zhuanglixi in south-central Shandong province.

A large amount of tartaric acid/tartrate in an ancient sample is a strong indicator of a grape product in the ancient Near East, but other sources need to be considered for China. Moreover, scholarly consensus has been that grape wine was first made from the domesticated Eurasian grape (Vitis vinifera vinifera), which was introduced into China from Central Asia during the second century B.C. (H. T. Huang 2000:240-242), some two millennia later than the Liangchengzhen mixed beverage. References to native grapes do occur-some as early as the Zhou period Shijing (Book of Odes, Qi Yue [seventh month], sect. Bin Feng; see Ma 1984:239)-but they are enigmatic. The texts do indicate, however, that grapes were appreciated for their sweetness and used in beverage making.

An especially strong candidate for the source of the tartaric acid/tartrate in the Liangchengzhen samples, instead of grape, is the Chinese hawthorn (Crataegus pinnatifida and C. cuneata, Shan Zha). This fruit contains four times the amount of tartaric acid in grape (Gao et al. 1995), and the modern distribution of hawthorn encompasses Shandong province as well as northern China (Chinese Academy of Science, Institute of Plant Research 1972:2:204-205). A high sugar content implies that it, like grape, could harbor yeast. Its nutritional and medicinal values were recognized early in Chinese culture, although it is not stated in any text that it was made into a beverage. Zhijun Zhao has identified the first archaeobotanical evidence in China for hawthorn fruit at Neolithic Jiahu.

Tartaric acid occurs in two other fruits, although in much lesser amounts than in grape (30 mg vs. $4 \mathrm{~g} / \mathrm{L}$ ): longyan (Euphoria longyan, Chinese herbal name Long Yan; Y.-W. Huang and C.-Y. Huang 1999:425) and Asiatic cornelian cherry (Cornus officialis, Shan Chu Yu; Hsu and Peacher 1982:193). The fruits of these trees, which are concentrated in the south today, are moderately sweet and some- 
what acidic. They probably grew as far north as southeastern Shandong province during the early and middle Longshan periods when temperatures were likely milder than today, especially along the Yellow Sea coast.

Other possible sources of tartaric acid/tartrate cannot be ruled out, but yield even lesser amounts of tartaric acid/tartrate $(0.1-2 \mathrm{mg} / \mathrm{L})$. Thus, the leaves of some plants (e.g., Pelargonium in the geranium family) have raphides of tartaric acid and calcium oxalate, which might be dispersed into a liquid by steeping (Stafford 1961). Saccharification of rice, which was the traditional method of Chinese beverage makers since at least the Han dynasty (ca. 206 B.C. -220 A.D.), also produces trace amounts of tartaric acid, depending on the mold used (F. Liu 1989; Maeda 1991; Y. Wang et al. 1991).

Scholars justifiably focus on the unique fermentation system for saccharifying rice and other grains during historical times, which would have precluded the need for the sugars or yeast provided by honey or fruit. In brief, saccharification or amylolysis fermentation (Chen et al. 1999; X. Fang 1989; H. T. Huang 2000:157-203, 258-282) exploits the fungi of the genera Aspergillus, Rhizopus, Monascus, and others, depending on environmental availability, to break down the carbohydrates of rice and other grains into simple, fermentable sugars. The thick mold mycelium was grown historically on a variety of steamed cereals, pulses, and other materials in making the fermentation agent (qu). Rice, as an early domesticate and one of the principal cereals of prehistoric China, presumably was an early substrate. Yeast enters the process adventitiously, either brought in by insects or falling from the rafters of old buildings and settling on to the large and small cakes of $q u$. As many as one hundred special herbs are used today to make $q u$, and some have been shown to increase the yeast activity as much as sevenfold (X. Fang 1942).

Before such a complicated system as amylolysis fermentation was developed and widely adopted by the ancient Chinese beverage maker, however, a more assured source of yeast would have been needed. The profusion and wide availability of wild grapes in China, as well as their high sugar content and the known availability of yeast for some species, argues strongly for their use in the Liangchengzhen mixed fermented beverage. The relatively high levels of tartaric acid/ tartrate in the ancient samples might also be explained by hawthorn tree fruit, although not yet attested at the site.

If mold amylolysis was not yet available to the Liangchengzhen beverage maker, (s)he had the additional problem of saccharifying the rice. No contemporaneous evidence bears on this important issue, but rice, like barley, is easily sprouted (germinated), releasing enzymes that break down its complex carbohydrates into fermentable simple sugars. Human saliva also contains a starchconverting enzyme (ptyalin), so that saccharification can be accomplished by chewing rice and collecting the moistened grain mass, as is reported among Japanese, Korean, Taiwanese; and Pacific Island peoples in recent times (see H.-T. Huang 2000:154, with references). In the New World, maize or corn beer (chicha) is still traditionally made by first chewing the grain; since corn is difficult to germinate, this saccharification technique could date back thousands of years there. Either this method or sprouting and drying the grain-i.e., maltingmight have been used in making the Liangchengzhen mixed beverage, before mold amylolysis was developed. 
Finally, our analyses suggest the presence of a plant resin or herb yet to be characterized. This finding is in accord with Shang dynasty inscriptions which refer to chang ("medicated wine"). During Zhou and Han times, chang is said to have been made by infusing resinous plant leaves or adding herbs $(y u)$ to the fermented beverage (H.-T. Huang 2000:157, 162, 232; Wen and Yuan 1983; Yang 1992).

While a mixed fermented beverage appears to explain best the consistent chemical evidence for the large group of Liangchengzhen pottery vessels, other explanations cannot be excluded. For example, it is possible that multiple reuse of types usually associated with cooking and food preparation/serving, such as the bizi steamer grate and pen basin, might explain the combined presence of rice, honey, fruit, and other ingredients. It should be noted, however, that a second pen and a probable cooking pot (ding) in the analytical corpus gave negative results. Furthermore, most of the vessels that were positive for the mixed beverage were drinking, serving, and/or storage vessel types that had been deposited in special contexts-tombs and possible dedicatory pits (see below). Vessels from such contexts were likely used only one time.

\section{SOCIAL AND RITUAL IMPLICATIONS}

The large percentage of pottery vessels that gave positive results for residues of a mixed fermented beverage raises questions about social and ritual activities at Liangchengzhen, specifically what mortuary and other rituals were practiced and what the functions of the many pits at this regional center were. All the vessels analyzed from medium-sized graves (M22, M23, M31; Figure 2) had held the beverage. In general, cups are the most common forms in these and other graves, which contained between four and fourteen vessels of both fine and coarse fabrics. Since burials of the previous Dawenkou period in Shandong province generally contained more pottery vessels and identifiable food remains (Underhill 2002), possibly the Liangchengzhen fermented beverage was given as offerings to the deceased, but was not drunk by mourners during a funeral feast.

An important role for the mixed fermented beverage in residential settings is also implied by the quantity and variety of vessel forms from pits that tested positive for its presence. As suggested for other Longshan sites (L. Liu 2000), some of these pits may have been used to present offerings to ancestors. Pit H31, for example, was filled with over two hundred whole or nearly whole vessels, and the beverage was attested for all seven vessels analyzed, including fine and coarse ware cups, $h u$ and lei jars, and gui tripods. The quantity and range of vessels point to drinking and perhaps feasting among ritual participants, followed by presentation of offerings. By contrast, other pits at Liangchengzhen appear to have been for residential storage or trash. For example, $\mathrm{H} 205$ was filled with sherds, rather than whole vessels, and an analyzed ding tripod from this pit did not contain the beverage. More generalized consumption of the beverage was evidenced by cups, gui tripods, $h u$, lei, and guan jars from other pits.

Intriguingly, unequivocal chemical evidence of the mixed beverage was obtained from a bizi steamer grate and a pen basin-both common Longshan forms-which are usually interpreted as being used for cooking or food preparation/serving, respectively. How is this to be explained? One hypothesis to be explored and tested is that these vessel forms had auxiliary functions in prepar- 
ing, filtering, and/or serving the beverage. Another possibility is that the mixed fermented beverage was used in cooking foods, like wine and beer find a place in food preparation in Western cultures.

The chemical analysis of pottery from the middle Longshan period at Liangchengzhen provides clear, contemporaneous evidence of what was being drunk and presumably presented in rituals of the late prehistoric period in Shandong province. Their uniform composition implies that set procedures were followed in fermenting the three main ingredients-rice, honey, and fruit. This well-made beverage paved the way for later technical developments. Its attestation at an important site near the coast of the Yellow Sea likely reflects similar developments occurring at inland centers along the Yellow River and at centers farther north and west.

Late Neolithic beverage makers at Liangchengzhen made use of the naturally available yeast in sugar-rich sources, including honey and fruit (most likely wild grape and/or hawthorn fruit), to ferment a rice beverage. It is probably not coincidental that what some scholars (Yuan 1989; and H.-T. Huang 2000:155-157, 259) believe to be the earliest Chinese fermented beverage (luo) likely was fruit based. The weng jars with fruit remains from the middle Shang site of Taixi (above) would then represent a continuation of a tradition reaching back into the Neolithic.

Complex urban life eventually led to different beverages and the amylolysis fermentation system, which became the standard method for making rice and millet "wine." Mixed fermented beverages, like that attested at Liangchengzhen, fell into abeyance, although the tradition of making an herbal rice wine concoction was never lost completely. Even today in many parts of China, including Shandong province, a popular drink (shouzhou mi jiu) has suspended fruit bits in rice wine.

Despite its somewhat different formulation from historical beverages, the Liangchengzhen mixed beverage would then have been stored, served up, drunk, and presented ceremonially in pottery vessels. Some of these forms were replicated in bronze during the Shang period, and new forms, sometimes analogous to earlier pottery shapes, made their appearance. The ceremonies and activities of everyday life in which these vessels were used presumably also have their basis in prehistory.

\section{CONCLUSIONS}

This study provides the first direct chemical evidence for the production and use of a fermented beverage during the late prehistoric (Longshan) period of northern China (for early Neolithic and Shang/Western Zhou Dynasty drinks, also see McGovern et al. 2004). For nearly forty years, scholars have relied on elegant pottery cups and jars, primarily from mortuary contexts, to argue for the existence of such a beverage. Now, this beverage has been identified from chemically extracted residues still preserved inside a variety of such vessels from both residential and mortuary contexts at Liangchengzhen. While the recent archaeological literature emphasizes the social and ritual roles of feasting, comparatively less attention has been paid to fermented beverages in these activities. The chemical and archaeological data for the Longshan period of China provide an important 
corpus of material for cross-cultural assessment of how people may use the production and consumption of fermented beverages for negotiating different kinds of social relationships, and how these activities may lead to economic and technological change.

It has been proposed on the basis of textual and archaeological data that rituals at early Bronze Age centers in northern China involved fermented beverages (Chang 1983; Keightley 1999; Underhill 2002). Moreover, these centers functioned at least in part as ceremonial centers (Chang 1983; Wheatley 1971). Longshan period centers probably had a similar function, judging from our evidence for fermented beverages at Liangchengzhen. In order to investigate this hypothesis more fully, we plan to test a wider sample of pottery vessels from the site and from our study region as a whole. We expect that more than one kind of ritual involving fermented beverages took place at regional centers, such as rituals restricted to elites accompanied by feasting and rituals for more than one social rank involving gifts of food and drink to ancestors. People who lived in surrounding, subsidiary settlements would have participated in some large, public rituals managed by elites at the center. Smaller sites should have less evidence for fermented beverages. Indeed, one strategy of Longshan period elites to increase power may have been to manage the production or distribution of fermented beverages.

We also plan to address methodological issues raised by our research. We will sample a wider range of vessel forms and larger quantities of vessels, including more forms that are believed not to have been used for a beverage and others (e.g., jars and cups) that might have had multiple uses. Although whole sherd extraction works well in recovering and targeting fingerprint compounds, we plan to test the degree of absorption of the fermented beverage into the pottery by extracting and testing separately the interior fabric, in which more liquid should have been absorbed and which should be less affected by the environment, and the exterior fabric. In addition, a wider variety of contexts will be sampled, including those that allow more intrasite comparisons by layer and by spatial area. Finally, by conducting experiments and other means, we intend to further investigate possible sources for marker compounds (e.g., tartaric acid) in the extracted residues, including saccharification of rice and the use of certain fruits.

\section{APPENDIX}

The chemical techniques employed in analyzing the Liangchengzhen pottery were as follows.

Diffuse-reflectance infrared Fourier-transform spectrometry (DRIFTS) takes advantage of the nature of chemical bonds to stretch and bend when they absorb infrared (IR) light. Each chemical compound absorbs IR light at specific frequencies that can be precisely measured and the principal absorptions can then be identified on a spectrum (Figure $5 a$ ). A milligram sample is needed for the microtechnique. Large databases of ancient samples and modern synthetic compounds and natural products are searched for the best matches. This technique has the advantage that the whole sample is analyzed simultaneously, although it also necessitates that the absorption peaks of individual compounds and functional groups be carefully distinguished. 
High-performance liquid chromatography (HPLC) is used for more precise identifications of mixed materials. Microgram amounts of each compound are separated from one another by dissolving the sample in a solvent and passing it at high pressure through a column lined with micron-sized particles. Depending on how strong the affinity or polarity is between the compound, moving solvent, and stationary substrate, the compound will take more or less time to pass through the column (referred to as the retention time). Specifically, methanol extracts of the Liangchengzhen samples were run on a relatively more polar (normal phase) column using a constant solvent (isocratic) flow. Once separated, the components are fed into an ultraviolet (UV) visible spectrophotometer diode array, ideally yielding characteristic absorptions by the compounds of interest.

An in-house database of several hundred ancient samples and modern reference compounds was then searched for the highest probability matches using HewlettPackard's A06.01 ChemStation software. Our database includes natural products (e.g., tree resins and beeswax), processed organic materials (such as modern wine, honey, grains, etc.), synthetic compounds generally occurring in the natural and processed organic materials of interest, and "ancient reference samples" (i.e., residues extracted from inscribed vessels that state they contain a particular beverage, food, spice/herb, resin, etc. and that are comprised of both intact and degraded components).

Gas chromatography/mass spectrometry (GC/MS), like HPLC, also enables microgram or smaller amounts of each compound to be separated on a column, after the sample has been volatilized as a gas. Briefly, our protocol was to run a 1 -ml chloroform extract of a pottery sherd on nonpolar fused silica columns optimized for sterol analyses. Since the samples were very small, valuable material was retained by not derivatizing them. Fractions coming off the column, which separates the components by boiling point, were fed into a quadrupole mass spectrometer, and masses from 50 to 450 were rapidly scanned. Total-ion scans were followed up by selected-ion monitoring, especially if an important component was at a low level. Normal paraffin and plant sterol standards were run to calibrate retention times and mass spectra. Several blank extractions were carried out to simulate the entire extraction process and analyzed to identify contaminants and other artifacts due to sample handling and preparation. Searches were made on the NIST mass spectral database to confirm the identity of the compounds.

Feigl (1966:470, 482-483) chemical spot tests for tartaric acid/tartrate and oxalate, with microgram sensitivity, take advantage of unique reactions. An observed fluorescence for the tartaric acid/tartrate test is critical, because other compounds (e.g., malic acid) can produce a green solution.

\section{ACKNOWLEDGMENTS}

We are grateful to the Henry Luce Foundation (1999; Underhill, Feinman, von Falkenhausen) and the National Science Foundation for supporting our excavations at Liangchengzhen (2000-2001; award BCS-9911128, Underhill and Feinman). Any opinions, findings and conclusions, or recommendations expressed in this material are those of the authors and do not necessarily reflect the views of the $\mathrm{Na}$ tional Science Foundation. We thank the National Bureau of Cultural Relics in Beijing for granting the excavation permit to our collaborative team. The faculty 
and headmasters of Liangchengzhen's Number One High School and Middle School generously provided McGovern with laboratory space. The GC/MS analyses were carried out in the chemistry department of Drexel University through the kind auspices of J. P. Honovich. Guangsheng Cheng, a retired professor of microbiology at Peking University, was untiring in his enthusiasm and help in explaining ancient and modern fermentation systems. Many scholars shared their knowledge with the authors and were helpful in the preparation of this paper: Carl Crook, Qin Ma Hui, Wuxiao Hong, Hsing-Tsung Huang, Jigen Tang, Shuicheng Li, Guoguang Luo, Victor Mair, Harold Olmo, Vernon Singleton, Tiemei Chen, and Changsui Wang. Jill Seagard, Department of Anthropology at the Field Museum, prepared Figures $1-4$.

\section{SPECIAL DEDICATION}

Dr. Donald Glusker, who worked closely with McGovern in analyzing ancient fermented beverage samples from Liangchengzhen, did not live to see the fruits of his labor. Don died unexpectedly on 11 May 2000 in Cambridge, England. He will be missed for his incisive mind, wit, good spirits, and enthusiasm for science in the cause of archaeology.

\section{REFERENCES}

ARTHUR, J.

2003 Brewing beer: Status, wealth and ceramic use alteration among the Gamo of southwestern Ethiopia. World Archaeology 34:516-528.

BRAY, T. L.

2003 The archaeology and politics of food and feasting in early states and empires. New York: Kluwer Academic/Plenum.

Cai, F., F. Luan, H. Yu, H. Fang, C. Sun, A. Underhill, G. Feinman, L. Nicholas, and G. BENNETT

1997 Rizhao Liangchengzhen diqu kaogu diaocha (Archaeological survey in the area around the site of Liangchengzhen at Rizhao). Kaogu (Archaeology) 4:289-303.

Cavalieri, D., P. E. McGovern, D. L. Hartl, R. Mortimer, and M. Polsinelli

2003 Evidence for S. cerevisiae fermentation in ancient wine. Journal of Molecular Evolution 57:S226-S232.

Chang, K. C.

1983 Art, Myth, and Ritual. Cambridge, MA: Harvard University Press.

Chen, T. C., M. TaO, and G. Cheng

1999 Perspectives on alcoholic beverages in China, in Asian Foods: Science and Technology: 383408, ed. C.Y.W. Ang, K. S. Liu, and Y.-W. Huang. Lancaster, PA: Technomic.

Childs-Johnson, E.

1988 The jue and its ceremonial use in the ancestral cult of China. Artibus Asiae 48:175-196.

Chinese Academy of Science, Institute of Plant Research

1972 Iconographia Cormophytorum Sinicorum (Zhongguo gaodeng zhiwu tujian). Beijing: Science.

CPAM of Henan Province, Xinyang District, and Luoshan County

1986 Luoshan Tianhu Shang Zhou mudi (The Shang and Zhou cemetery at Tianhu, Luoshan County). Kaogu Xuebao (Bulletin of Archaeology) 2:153-197.

CRAWFORD, G.

1992 Prehistoric plant domestication in East Asia, in The Origins of Agriculture: An International Perspective: 7-38, ed. C. W. Cowan and P. J. Watson. Washington, D.C.: Smithsonian Institution. 
Crawford, G., A. Underhill, Z. Zhao, G.-A. Lee, G. Feinman, L. Nicholas, F. Luan, H. Yu, H. FANG, AND F. CAI

2004 Shandong Rizhao shi Liangchengzhen yizhi Longshan wenhua zhiwu yicun de chubu fenxi (Analysis of plant remains unearthed from the Longshan culture site of Liangchengzhen in Rizhao City, Shandong). Kaogu (Archaeology) 9:73-80.

2005 Late Neolithic plant remains from northern China: Preliminary results from Liangchengzhen, Shandong. Current Anthropology 46(2):309-316.

Dematte, P.

1999 Longshan-era urbanism: The role of cities in predynastic China. Asian Perspectives $38(2): 131-153$.

DietLer, $M$.

1990 Driven by drink: The role of drinking in the political economy and the case of early Iron Age France. Journal of Anthropological Archaeology 9:352-406.

Dietler, M., and B. Hayden (eds.)

2001 Feasts: Archaeological and Ethnographic Perspectives on Food, Politics, and Power. Washington, D.C.: Smithsonian Institution.

Evershed, R. P., S. J. Vaughan, S. N. Dudd, and J. S. Soles

1997 Fuel for thought? Beeswax in lamps and conical cups from late Minoan Crete. Antiquity $71: 979-985$.

Fang, H., F. Luan, H. Yu, F. Cai, A. Underhill, G. Feinman, L. Nicholas, and G. Bennett

2002 Shandong Rizhao diqu xitong quyu diaocha de xin shouhuo (New results from the systematic, regional survey in the Rizhao district of Shandong). Kaogu (Archaeology) 5:1018.

FANG, $\mathrm{X}$.

1942 Weijun shengzhangsu shiyan (Experiments on growth factors for microorganisms). Huanghai (Yellow Sea) 4(2):35-40.

1989 Zailun woguo qu nie niangiu de qiyuan yu fazhan (Reexamination of the origin and development of fermenting agents in Chinese wine fermentation), in Zhongguo Jiи Wenhua (Chinese wine culture): 3-31, ed. Y. Li. Beijing: China Food.

FANG, Y.

1964 Wo guo niang jiu dang shiyu Longshan wenhua (The fermentation of wine in our country during the Longshan culture). Kaogu (Archaeology) 2:94-97.

Feigl, F. (in collaboration with V. Anger)

1966 Spot Tests in Organic Analysis, 7th ed., trans. R. E. Oesper. Amsterdam: Elsevier.

Fung, C.

2000 The Drinks Are on Us: Ritual, Social Status, and Practice in Dawenkou Burials, North China. Journal of East Asian Archaeology 2(1/2):67-92.

GAO, G. Y., Y. X. FenG, AND X. Q. QIN

1995 Shanzhaguo de huaxue zuchen fenxi he binzhi jianding (Analysis of the chemical constituents of hawthorn fruit and their quality evaluation). Yaoxue Xuebao (Bulletin of Pharmacology) $30(2): 138-143$.

Guasch-Jané, M. R., M. Ibern-Gómez, C. Andrés-Lacueva, O. Jáuregui, and R. M. LamuelaRAVENTÓS

2004 Liquid chromatography with mass spectrometry in tandem mode applied for the identification of wine markers in residues from ancient Egyptian vessels. Analytical Chemistry $76: 1672-1677$.

Guo, S. Q.

1986 Luelun Yin Dai de zhi jiu ye (Discussion of the wine industry during the Shang dynasty). Zhongyuan Wenwu (Cultural Relics of the Central Plain) 3:94-95.

Hastorf, C., AND S. JOHANNESSEN

1993 Pre-Hispanic political change and the role of maize in the central Andes of Peru. American Anthropologist 95(1): 115-138.

HAYDEN, B.

1995 Pathways to power: Principles for creating socioeconomic inequalities, in Foundations of Social Inequality: 15-86, ed. T. Price and G. Feinman. New York: Plenum. 
Hebei Provincial Institute of Cultural Relics and Archaeology

1985 Gaocheng Taixi Shang Dai Yizhi (The Shang site of Taixi at Gaocheng). Beijing: Wenwu.

Henan Provincial Institute of Cultural Relics and Archaeology

1999 Wuyang Jiahu, vols. 1 and 2. Beijing: Science.

Hsu, H.-Y., AND W. G. Peacher (eds.)

1982 Chinese Herb Medicine and Therapy. New Canaan, CT: Keats.

HuANG, H.-T.

2000 Biology and Biological Technology, Part V: Fermentations and Food Science, in Science and Civilisation in China, vol. 6. Cambridge: Cambridge University Press.

HuANG, Y.-W., AND C.-Y. HuANG

1999 Traditional Chinese functional foods, in Asian Foods: Science and Technology: 409-452, ed. C.Y.W. Ang, K. S. Liu, and Y.-W. Huang. Lancaster, PA: Technomic.

Institute of Archaeology, Chinese Academy of Social Sciences

1984 Xin Zhongguo De Kaogu Faxian He Yanjiu (Archaeological research and discoveries in new China). Beijing: Wenwu.

JOFFE, A.

1998 Alcohol and social complexity in ancient western Asia. Current Anthropology 39(3):297322.

Keightley, D.

1999 The Shang: China's first historical dynasty, in The Cambridge History of Ancient China: 232-291, ed. M. Loewe and E. Shaughnessy. Cambridge: Cambridge University Press.

Kolattukudy, P. E. (ED.)

1976 Chemistry and Biochemistry of Natural Waxes. Amsterdam: Elsevier.

Kong Z., C. LiU, AND D. HE

1999 Shandong Tengzhou Shi Zhuanglixi yizhi zhiwu yicun ji qi zai huanjing kaoguxue shang de yiyi (Significance for environmental archaeology about the plant remains preserved at the site of Zhuanglixi at Tengzhou City, Shandong). Kaogu (Archaeology) 7:59-62.

LEE, Y. K.

2002 Building the chronology of early Chinese history. Asian Perspectives 41(1):15-42.

LI, J. M.

1984 Dawenkou muzang chutu de jiu qi (Wine vessels excavated from burials at Dawenkou).

Kaogu Yu Wenwu (Archaeology and Cultural Relics) 6:64-68.

LI, Y. S.

1993 Wo guo guwu niang jiu qiyuan xin lun (A new discussion on the origins of wine made from grain in our country). Kaogu (Archaeology) 6:534-542.

LiU, F.

1989 Huangjiu zhong buhuifasuan zufen de fenxi yanjiu (Studies on analysis of nonvolatile acids in rice wine). Shipin Yu Faxiao Gongye (Food and Fermentation Industry) 3:16-29.

LiU, L.

1996a Mortuary ritual and social hierarchy in the Longshan culture. Early China 21:1-46.

19966 Settlement patterns, chiefdom variability, and the development of early states in North China. Journal of Anthropological Archaeology 15(3): 237-288.

2000 Ancestor worship: An archaeological investigation of ritual activities in Neolithic North China. Journal of East Asian Archaeology 2(1/2):129-164.

2003 "The products of minds as well as of hands": Production of prestige goods in the Neolithic and early state periods of China. Asian Perspectives 42(1):1-40.

LIU, L., AND X. C. CHEN

2001 Settlement archaeology and the study of social complexity in China. Review of Archaeology 22(2): 4-22.

Lockheart, M. J., P. F. van Bergen, and R. P. Evershed

2000 Chemotaxonomic classification of fossil leaves from the Miocene Clarkia Lake deposit, Idaho, USA based on n-alkyl lipid distributions and principal component analyses. Organic Geochemistry $31: 1223-1246$. 
LUAN, F. S.

1992 Shandong Longshan wenhua shehui jingji chutan (Preliminary discussion of the economy and society of the Shandong Longshan culture), in Shandong Longshan Wenhua Yanjiu Wen $J i$ (Collection of essays on research on the Shandong Longshan culture): 247-266, ed. F. S. Cai and F. S. Luan. Jinan: Ji Lu.

1996 Dongyi kaogu (Archaeology of the eastern Yi). Jinan: Shandong University Press.

Luan, F. S., H. G. Yu, F. S. Cai, H. Fang, P. Vandiver, A. Underhill, G. Feinman, and L. Nicholas

in press Rizhao Liangchengzhen de Taoqi Jishu (Pottery technology at Liangchengshen in Rizhao). Kaogu (Archaeology).

MA, C. Y.

1984 Shijing Jin Zhu Jin Yi (A modern translation of the Shijing). Taipei: Shangwu.

MAEDA, M.

1991 Chūgokusan aka miso ni tsuite (Study of production of Chinese red miso). Nagasaki-ken Kögyo Gijutsu Senta Kenkyū Hokoku (Reports of Nagasaki Industrial Technology Research Center) 8:112-114.

McGovern, P. E.

1997 Wine of Egypt's golden age: An archaeochemical perspective. Journal of Egyptian Archaeology $83: 69-108$.

1999- Unpublished chemical data on file. MASCA, Molecular Archaeology Laboratory, Uni2000 versity of Pennsylvania Museum.

2000 The funerary banquet of "King Midas." Expedition 42:21-29.

2003 Ancient Wine: The Search for the Origins of Viniculture. Princeton, NJ: Princeton University Press.

McGovern, P., H. Fang, A. Underhill, F. Luan, H. Yu, C.-S. Wang, F. Cai, G. Hall, G. FeinMAN, AND Z. ZHAO

2005 Shandong Rizhao Liangchengzhen yizhi Longshan wenhua jiu yicun de huaxue fenxijian tan jiu zai shiqian shiqi de wenhua yiyi (Chemical analysis of preserved alcoholic beverage from the Longshan culture site of Liangchengzhen in Rizhao, Shandong: A preliminary discussion of the cultural significance of alcohol production during the prehistoric period). Kaogu (Archaeology) (forthcoming).

McGovern, P. E., J. Zhang, J. Tang, Z. Zhang, G. R. Hall, R. A. Moreau, A. Nuñez, E. D. Butrym, M. Richards, C.-S. Wang, G. Cheng, Z. Zhao, and C. Wang

2004 Fermented beverages of pre- and proto-historic China. Proceedings of the National Academy of Science $101: 17593-17598$.

McGovern, P. E., S. J. Fleming, and S. H. Katz (eds.)

1995 The Origins and Ancient History of Wine. Luxembourg: Gordon and Breach.

McGovern, P. E., D. L. Glusker, R. A. Moreau, A. Nuñez, C. W. Beck, E. Simpson, E. D. Butrym, L. J. Exner, And E. C. Stout

1999 A funerary feast fit for King Midas. Nature 402:863-864.

McGovern, P. E., U. Hartung, V. R. Badler, D. L. Glusker, and L. J. Exner

1997 The beginnings of winemaking and viniculture in the ancient Near East and Egypt. Expedition 39(1):3-21.

McGovern, P. E., AND R. H. Michel

1990 Royal purple dye: The chemical reconstruction of the ancient Mediterranean industry. Accounts of Chemical Research $23: 152-158$.

McGovern, P. E., M. M. Voigt, D. L. Glusker, And L. J. Exner

1996 Neolithic resinated wine. Nature 381:480-481.

Merk, S., A. Blume, ANd M. Riederer

1998 Phase behaviour and crystallinity of plant cuticular waxes studied by Fourier transform infrared spectroscopy. Planta 204:44-53.

Michel, R. H., J. LAzar, AND P. E. McGovern

1992 The chemical composition of the indigoid dyes derived from the hypobranchial glandular secretions of Murex mollusks. Journal of the Society of Dyers and Colourists 108:145-150.

Michel, R. H., P. E. McGovern, And V. R. Badler

1992 Chemical evidence for ancient beer. Nature 360:24. 
Mills, J. S., AND R. White

1994 The Organic Chemistry of Museum Objects, 2nd ed. Oxford: Butterworth-Heinemann.

MOORE, J.

1989 Pre-Hispanic beer in coastal Peru: Technology and social context of prehistoric production. American Anthropologist 91(3):682-695.

Morohashi, T.

1987 Dai Kan Wa Jiten (Large-scale Chinese-Japanese dictionary). Taipei: Heng Sheng.

PAPER, J.

1995 The Spirits Are Drunk. Albany: State University of New York Press.

Pauketat, T., L. S. Kelly, G. J. Fritz, N. H. Lopinot, S. Elias, and E. Hargrave

2002 The residues of feasting and public ritual at early Cahokia. American Antiquity 67:257279.

POTTER, J. M.

2000 Pots, parties, and politics: Communal feasting in the American southwest. American Antiquity $65: 471-492$.

QIU, S. H., AND L. Z. CAI

2001 Xia Shang Zhou duandai gongcheng zhong de tanshisi niandai kuangjia (A ${ }^{14} \mathrm{C}$ dating framework for the Xia-Shang-Zhou chronology project). Kaogu (Archaeology) 1:90100.

RAwSON, J.

1993 Ancient Chinese ritual bronzes: The evidence from tombs and hoards of the Shang (c. 1500-1050 B.C.) and Western Zhou (c. 1050-771 в.с.) Periods. Antiquity 67:805-823.

Reddy, C. M., T. I. Eglinton, R. Palic, B. C. Benitez-Nelson, G. Stojanovic, I. Palic, S. DJORDJEVIC, AND G. EgLINTON

2001 Even carbon number predominance in plant wax n-alkanes: A correction. Organic Geochemistry $31: 331-336$.

Rizhao City Library and Linyi District Committee for Management of Cultural Relics

1986 Shandong Rizhao Longshan wenhua yizhi diaocha (Survey of Longshan culture sites in Rizhao county, Shandong). Kaogu (Archaeology) 8:680-702.

SHUSEN, D.

2001 A black horse galloping through western China. China Today 50(11):65-69.

Sківо, J.

1992 Pottery Function: A Use-Alteration Perspective. New York: Plenum.

STAFFORD, H. A.

1961 Distribution of tartaric acid in the Geraniaceae. American Journal of Botany 48(8):699-701.

Staller, J. E., and R. G. Thompson

2002 A multidisciplinary approach to understanding the initial introduction of maize into coastal Ecuador. Journal of Archaeological Science 29:33-50.

THORP, R.

1985 The growth of early Shang civilization: New data from ritual vessels. Harvard Journal of Asiatic Studies 45(1):5-75.

Tu, T.N.T., S. Derenne, C. Largeau, A. Mariotti, and H. Bocherens

2001 Evolution of the chemical composition of Gingko biloba external and internal leaf lipids through senescence and litter formation. Organic Geochemistry 32:45-55.

UNDERHILL, A.

1996 Craft production and social evolution during the Longshan period of Northern China, in Craft Specialization and Social Evolution: In Memory of V. Gordon Childe: pp. 133-150, ed. B. Wailes. University Museum Monographs, Symposium Series. Philadelphia: University Museum of Archaeology and Anthropology, University of Pennsylvania.

2000 An analysis of mortuary ritual at the Dawenkou site, Shandong, China. Journal of East Asian Archaeology 2(1/2): 93-127.

2002 Craft Production and Social Change in Northern China. New York: Kluwer Academic/ Plenum.

n.d. Archaeological and textual evidence for the production and use of alcohol in China, in Proceedings from the Ninth Yale-Smithsonian Seminar on Material Culture: Fermented and Distilled: ed. D. Kops. 
Underhill, A., G. Feinman, L. Nicholas, G. Bennett, F. S. Cai, H. G. Yu, F. S. Luan, and H. FANG

1998 Systematic, regional survey in SE Shandong Province, China. Journal of Field Archaeology $25(4): 453-474$.

Underhill, A., G. Feinman, L. Nicholas, G. Bennett, H. Fang, F. S. Luan, H. G. Yu, and F. S. CAI

2002 Regional survey and the development of complex societies in southeastern Shandong, China. Antiquity 76:745-755.

WANG, R. (ED.)

1997 Zhongguo shiqian chuishi shi (A history of cooking in prehistoric China). Qingdao: Qingdao City.

Wang, Y., L. Li, AND Y. Sun

1991 Gaoxiao yixiang sepufa fenxi sejiu zhong youjisuan de yanjiu (Determination of organic acids in rice wine by high performance liquid chromatography). Sepu (Chinese Journal of Chromatography) 9:271-272.

WeN, S. F., AND T. D. YUAN

1983 Yinxu Buci Yanjiu: Kexue Jishu Pian (Research on Shang oracle bone inscriptions: Technical scientific division). Chengdu: Sichuan Province Social Science.

Wheatley, P.

1971 The Pivot of the Four Quarters. Edinburgh: Edinburgh University.

White, R.

1978 The application of gas-chromatography to the identification of waxes. Studies in Conservation 23:57-68.

Xin Xiv Ben Cao (Newly improved pharmacopoeia)

1985 Shanghai: Gu Ji.

XING, R., AND Y. TANG

1984 Archaeological evidence for ancient wine making, in Recent Discoveries in Chinese Archaeology: 56-58, ed. F. Stockwell and T. Bowen, trans. B. Zuo. Beijing: Foreign Languages.

Xu, J., Q. Zhou, H. YAng, S. Lin, AND L. Luo

1989 Zhonghua mifeng yu yidali mifeng fengla chenfen yanjiu (Study on the compositions of beeswax of Apis Cerana and Apis Mellifera). Sepu (Chinese Journal of Chromatography) $7(3): 175-176$.

YANG, S. N.

1992 Shang Dai Jingji Shi (A history of the Shang dynasty). Guiyang: Guizhou Peoples.

YIN, D.

1955 Xin Shiqi Shidai (The Neolithic period). Beijing: Sanlian.

YUAN, H.

1989 Niangjiu zai woguo de qiyuan he fazhan (The origin and development of wine fermentation in China), in Zhongguo Jiu Wenhua (Chinese wine culture): 35-62, ed. Y. Li. Beijing: China Food.

ZHANG, D. S.

1994 Yin Shang jiu wenhua chulun (Preliminary discussion about the Shang wine culture). Zhongyuan Wenwu (Cultural Relics of the Central Plain) 3:18-24.

ZHANG, F., L. FANGMEI, AND G. DaBin

1990 Studies on germplasm resources of wild grape species (Vitis Spp.) in China, in Proceedings of the 5th International Symposium on Grape Breeding: 12-16 September 1989, St. Martin/ Pfalz, FR Germany: 50-57, ed. Bundesforschungsanstalt für Rebenzüchtung (special issue of Vitis). Siebeldingen, Germany: Verlag der Bundesforschungsanstalt für Rebenzüchtung Geilweilerhof.

ZHANG, Y. H., AND D. H. ZHANG

1986 Zhongyuan diqu Longshan wenhua de leixing he niandai (Types and periods of Longshan culture in the Central Plain), in Zhongguo Kaoguxue Yanjiu: Xia Nai Xiangsheng Kaogu Wushi Nian Jinian Lunwenji (Research in Chinese archaeology: Collection of essays to commemorate 50 years of archaeology with Mr. Xia Nai): 46-56, ed. Committee of Archaeological Research in China. Beijing: Wenwu. 
ZHANG, Z.

1960 Lun wo guo niangiu qiyuan de shidai wenti (Regarding the date of origin of wine fermentation in China). Qinghua Daxue Xuebao (Bulletin of Qinghua University) 7(2):3133.

ZHu, Hong

1964 Bei Shan Jiu Jing (Wine canon of North Hill). Taipei: Xing Zhong Shu Ju.

\section{ABSTRACT}

Humans around the world have shown a remarkable propensity to ferment available sugar sources into alcoholic beverages. These drinks have contributed significantly to cultural innovation and development, including agricultural and horticultural skills to harness natural resources; technologies to produce the beverages and to make special vessels to serve, drink, and present them ceremonially; and their incorporation into feasting and other activities. Molecular archaeological analyses of a range of pottery forms from the site of Liangchengzhen, China, illustrates how contemporaneous chemical data, in conjunction with intensive archaeological and botanical recovery methods, enables the reconstruction of prehistoric beverages and their cultural significance. During the middle Longshan period (ca. 2400-2200 B.C.), a mixed fermented beverage of rice, fruit (probably hawthorn fruit and/or grape), and possibly honey was presented as grave offerings and consumed by the residents of the regional center. 